\title{
Application of Nonlinear Static Procedures for Seismic Assessment of Regular RC Moment Frame Buildings
}

\author{
Michalis Fragiadakis ${ }^{1}$, Dimitrios Vamvatsikos ${ }^{2}$, Mark Aschheim ${ }^{3}$ \\ ${ }^{1}$ Department of Civil and Environmental Engineering, University of Cyprus, mfrag@mail.ntua.gr \\ ${ }^{2}$ School of Civil Engineering, National Technical University of Athens, Greece, divamva@mail.ntua.gr \\ ${ }^{3}$ Department of Civil Engineering, Santa Clara University, CA, maschheim@scu.edu
}

\begin{abstract}
The applicability of nonlinear static procedures for estimating seismic demands of typical regular RC moment-resisting frames is evaluated. This work, conducted within the framework of the ATC-76-6 project, shows the degree to which nonlinear static methods can characterize global and local response demands vis-à-vis those determined by nonlinear dynamic analysis for three RC moment frame buildings. The response quantities (engineering demand parameters) considered are peak story displacements, story drifts, story shears and floor overturning moments. The single-mode pushover methods evaluated include the N2 and the ASCE-41 coefficient methods. Multi-modal pushover methods such as the Modal Pushover Analysis and the Consecutive Modal Pushover method also were evaluated. The results indicate that the relatively good performance of the single-mode methods observed for low-rise buildings rapidly deteriorates as the number of stories increases. The multimode techniques generally extend the range of applicability of pushover methods, but at the cost of additional computation and without ensuring reliability of the results.
\end{abstract}

Keywords: Seismic performance assessment, Static Pushover, Nonlinear Static Procedures, Nonlinear Response History Analysis, Modal Pushover Analysis.

\section{INTRODUCTION}

Nonlinear Static Procedures (NSPs) are popular for the evaluation of buildings subjected to earthquake loading, and are being considered for use in the design of new buildings in the proposed updates to ASCE 31 and 41. However, Nonlinear Response History Analysis (NRHA) is generally recognized as the most rigorous analysis method available. The attractiveness of NSPs is attributed to the greater computing cost of NRHA, the difficulty of selecting appropriate ground motions and scale factors, and the fact that NSP is closer to the simpler elastic-static methods traditionally used for seismic design in building codes worldwide.

For a single-story, lightly damped, single-degree-of-freedom structure, the difference in the results of a NSP and NRHA is expected to be small. However, as the number of stories, and thus the number of the natural modes of vibration, increase, the prominence of the first mode of response 
generally diminishes. Dispersion in response quantities results due to the varying frequency content of ground motion excitations and the timing of interacting modal responses. As well, the sensitivity of response quantities to higher mode content varies with the response quantity and location within the structure. The notion of a "mode" can be applied to structures undergoing nonlinear response (e.g. Aschheim et al. 2002), and accommodates the influence of material inelasticity on the instantaneous mode shape and frequency.

Questions about the accuracy and utility of nonlinear static methods have been raised in recent years. For example, limitations of nonlinear static procedures were identified in the ATC-55 project (FEMA-440 2005), but the multi-story building models considered were too few in number to allow the domain of applicability of these procedures to be accurately characterized. Thus, one objective of this study, conducted under the auspices of the ATC 76-6 project (NIST 2010), is to evaluate error, relative to nonlinear dynamic analysis results, to better identify the domain of applicability of single and multi-mode pushover procedures. The procedures include common NSPs, such as those identified in the ASCE/SEI 41-06 (2007) guidelines and also more elaborate NSPs that attempt to enhance the capability of the typical NSP in order to provide results closer to those of NRHA. Given the inherent inability of simple nonlinear static methods of analysis to reflect the diversity of response apparent in NRHA, accuracy of the NSP methods is evaluated relative to the central tendency (mean or median) of the chosen response parameters.

\section{NONLINEAR STATIC ANALYSIS METHODS}

\section{Problems and Limitations}

Linear static methods of analysis (e.g. the Equivalent Lateral Force procedure) have been used successfully for design. However, for analysis, such as in the evaluation of existing and potentially deficient structures, the applicability of nonlinear static methods merits examination because their theoretical basis is not robust. The assumption that the response of a multi-degree of freedom system is directly related to the response of an equivalent single-degree of freedom (SDOF) system depends on the sensitivity of the response parameter of interest to higher modes of vibration and the degree to which these modes are excited. Also, peak values of different response parameters, also termed Engineering Demands Parameters (EDPs), may occur at different times in the NRHA due to the nature of the ground motion excitation and its effects on modal interaction in the context of potentially inelastic and possibly degrading component response. Peak values of the same type of EDP at different locations in the structure also may occur at different times and be more or less sensitive to contributions from each mode.

The inherent simplicity of conventional NSPs limits their ability to represent these effects well. In the simplest NSPs, the lateral load pattern is applied without taking into consideration member yield- 
ing, the resulting modification of dynamic properties with changes in component stiffness, and the potential interaction of multiple modes. Improved NSPs including multi-modal methods attempt to improve the estimate obtained using nonlinear static analysis methods at the expense of complicated computations (Fragiadakis et al. 2007). However, these approaches tend to involve simplifying assumptions derived more on engineering judgment and intuition rather than being conceptually robust and numerically justified. Nevertheless, NSP is a valuable tool that is useful in conjunction with an NRHA in order to gain a sense for the response characteristics of the structure, and to check the numerical model.

Kunnath and Erduran (2008) have shown that not only are the results of NRHA affected by modeling choices, but the evaluation of adequacy of an approximate method is a function of these modeling choices. Divergence in the story drifts determined by different analysis methods were observed depending on whether P-delta effects were modeled or not. Similarly, record-to-record variability was shown to affect story drift demands determined by NRHA differently from those determined by pushover analysis. One explanation for these observations might be that these modeling and ground motion choices affected the inelastic mechanism that developed during response. Clearly, an evaluation of the accuracy of pushover methods relative to results obtained by NRHA is conditioned on assumptions made in modeling.

Nonlinear dynamic response of structures involves fairly complex interactions among the evolving modes of the structure (Aschheim et al. 2002, Haselton and Deierlein 2007). The development of different inelastic mechanisms will increase dispersion in the values of at least some EDPs of interest. Nonlinear static methods generally are incapable of representing the development of multiple inelastic mechanisms and the variety of modal interactions and timing that produce maxima in the NRHAs. There are cases, where nonlinear static methods may tend to exaggerate deformation demands where mechanisms are determined to occur, while underestimating deformation demands that are observed to occur at other locations in nonlinear dynamic analysis.

\section{Summary of existing NSP methods and previous comparative studies}

Non-adaptive multimodal pushover methods such as Modal Pushover Analysis (MPA) (Chopra and Goel 2002) and its variant, Modified Modal Pushover Analysis Method (MMPA) (Goel and Chopra 2005), as well as adaptive single and multi-modal pushover methods have been developed as enhanced methods that promise more accurate response quantity estimates. MMPA was conceived in order to avoid difficulties posed by reversals in higher mode capacity curves observed in the FEMA P-695 (FEMA 2009) project and makes the simplification of assuming that higher modes remain elastic, while energy-based pushovers (e.g. Hernández-Montes et al. 2004) provide alternative means to consider nonlinearity in the modal pushovers. When presented by Chopra and Goel (2002) and Goel and Chopra (2005), the MPA and MMPA were suggested for estimating peak floor (or roof) 
displacements and story drifts; inaccuracy in the estimation of peak plastic hinge rotations was recognized early on. A subsequent modification extended the MPA method to determine member forces and moments by imposing computed deformations on the structural model in a second analysis phase (Goel and Chopra 2005); this was necessary for those cases where modal combinations in the MPA and MMPA procedures resulted in forces in excess of member capacities (e.g. beam shears exceeding the shears that occur when plastic hinges develop at the ends of a beam). Nevertheless, practitioners and researchers seem reluctant to perform this additional analysis step, and usually determine all response quantities in a single application of the MPA or MMPA procedure using the square root of the sum of the squares (SRSS) combination of the response quantities obtained in each independent modal pushover analysis.

Önem (2008) considered various single and multiple mode pushover methods as applied to moment frames and dual systems. Of note are some procedures which combine multi-modal effects at each step in the pushover analysis, such as Incremental Response Spectrum Analysis (IRSA) (Aydinoglou 2003) and Displacement Adaptive Pushover (DAP) (Antoniou and Pinho 2004). Önem (2008) confirms that first mode pushover analysis produced accurate estimates of peak floor displacements for low- and mid-rise structures, but tend to overestimate peak displacements for taller structures. More complex methods sometimes provided better estimates relative to the estimates obtained using the simpler pushover procedures, but no method was identified that could provide consistently reliable estimates for every EDP and building considered.

Diotallevi et al. (2008) applied various single load vectors ( $1^{\text {st }}$ mode, triangular, and SRSS), adaptive pushover methods, and MPA) to reinforced concrete (RC) frames. MPA resulted in the least average error of all methods considered for estimates of story shears for nearly every building (regular and irregular) examined. However, the best method to use for story drifts was less clear, as some methods were better than others for particular buildings. Kalkan and Kunnath (2007) considered RC moment frames and reports that the FEMA-356 procedure underestimates interstory drifts at the upper stories and overestimates story drifts in the lower stories, while the MMPA method may underestimate or overestimate interstory drifts at the upper stories. They also report that the MMPA was inconsistent in its ability to identify yielding in potential plastic hinges.

The preceding studies leave a mixed impression as to the ability of the MPA and MMPA procedures to provide accurate estimates of peak floor displacements, story drifts, plastic hinge rotations, and story shears. Results reported in FEMA-440 (FEMA 2005) illustrate that the accuracy of the MMPA procedure varies with structural system/configuration and drift level (or intensity of inelastic response). The accuracy of the MMPA estimates of story shears and floor overturning moments degraded significantly as the 3-story steel moment frame was driven to higher drifts and was poor at a peak roof drift of $4 \%$. The introduction of a weak story into a 9-story steel moment frame caused the 
accuracy of the MMPA estimates of story shears to degrade substantially. Goel (2005) reports that the MPA procedure does not lead to a reasonable estimate of the response where a soft first story exists.

A complete literature review on NSP methods can be found in Appendix H of NIST (2010). Of particular interest is the classic paper by Krawinkler and Seneviratna (1998) and the papers on bridges by Pinho et al. (2007, 2009). Moreover, an interesting contribution comes from Kunnath (2007) who investigates the evolution of force patterns during nonlinear response history analysis in order to identify appropriate modal lateral load patterns. The applicability and the accuracy of different pushover methods are also discussed and compared in Kalkan and Kunnath (2007), Isaković and Fischinger (2011), Causevic and Mitrovic (2011) and Lagaros and Fragiadakis (2011). Finally, the topic of plan irregular structures has been looked at by Bhatt and Bento (2012). Despite this abundance of studies on the validity of the NSP, a consensus has not yet been reached regarding its range of applicability. This was the driving force behind the ATC-76-6 project (NIST 2010), the most significant results of which pertaining to reinforced concrete buildings are presented in the following.

\section{Applicability of NSP methods in US Guidelines}

Recent documents and guidelines discuss the application of alternative analysis methods, including NSP procedures. In general, according to their complexity, a hierarchy among the methods is proposed. The possible analysis methods are: linear static procedure (LSP), linear dynamic procedure (LDP), nonlinear static procedure (NSP) and nonlinear dynamic procedure (NDP). This terminology is adopted by ASCE/SEI 31-03 (2003) and FEMA-440 (FEMA 2005), while ASCE/SEI 7-10 (2010) and FEMA P750 (2009) suggest equivalent lateral force (ELF) (approximately equivalent to LSP), modal response spectrum analysis (MRSA) (approximately equivalent to LDP), and seismic response history (SRH) (approximately equivalent to NRHA or NDP). Guidance is provided in these documents to facilitate the choice of analysis procedure with regard to parameters including: (i) building height, (ii) number of stories, (iii) first-mode period, and (iv) damage-to-capacity ratio (DCR). For example, ATC-40 (1996) recommends that linear analysis procedures are acceptable for "simple" structures, while for buildings with $T>1 \mathrm{sec}$, NRHA must be adopted. ASCE-31 recommends that more elaborate methods (LDP, NSP or NDP) should be used when $T \geq 3.5 T_{\mathrm{s}}$, where $T_{\mathrm{s}}$ is the corner period (at the junction of the constant acceleration and constant velocity portions of the design spectrum.) Restrictions with respect to irregularities (in plan and/or elevation) are also identified.

According to FEMA-440 (2005), linear elastic analysis may be adopted where the structure is expected to remain elastic or nearly elastic, or where the design results in nearly uniform distribution of nonlinear response throughout the structure. Morevoer, it is stated that: "the dividing line between buildings for which reliable results can be obtained using NSPs and those for which the results cannot be relied upon is nebulous". Thus, the NSP method should be applied when criteria that cover 
a series of parameters are met: (i) EDP of interest: the method is adequate for story drifts for low-rise buildings and wall buildings. It is stated that "for virtually all cases the simplified procedures produce unreliable estimates for story shears and overturning moments." (ii) Degree of inelasticity: NSP is adequate for slight or moderate levels of inelasticity. (iii) Period of vibration: the threshold on periods is set to $2 T_{\mathrm{s}}$. The limit is smaller when story shears are sought. (iv) Structural system type: The NSP may not be as reliable for shear wall structures. (v) Post-elastic strength: the NSP may not be as reliable where significant P-Delta effects or strength loss are present in the form of post-elastic negative tangent stiffness. This is measured with the $R_{\max }$ quantity, i.e. a conservative estimate of the available collapse capacity of the system expressed in terms of a maximum allowable reduction factor and calculated from the properties of the NSP capacity curve. (vi) Inelastic mechanism: Forces associated with the second and higher modes may affect the inelastic mechanism. Thus, NSP may not identify the governing mechanism correctly. This is particularly apparent where different collapse mechanisms occur under different ground motion excitations (e.g. Haselton and Deierlein 2007).

ASCE-41 (2007) suggests that linear procedures (LSP and LDP) are not permitted for buildings with one or more significant irregularities and one or more component DCRs (Damage-Capacity Ratios) that exceed 2. ASCE-41 also states that modal response spectrum analysis must be performed using modes that achieve at least 90\% modal participation, or, in orther words, include as many modes as required so that the sum of their modal contribution factors is equal to or greater than $90 \%$. This criterion is intended to capture situations in which higher modes are significant. However, FEMA-440 identified cases where the first mode achieved greater than $90 \%$ modal participation but NSP results were poor.

\section{NSP methods considered in the framework of ATC-76-6}

Enhanced multi-modal methods are being used to augment NSPs in current practice. The enhanced methods aim to improve the accuracy of nonlinear static analysis, ultimately aiming to avoid NRHA. Generally, experience with these methods is quite limited, and their relative complexity is a barrier to implementation. Furthermore, the increased complexity and potential for inconsistent reliability has to be weighed relative to the use of NRHA. For example, as reported in FEMA 440, NRHA using even a single ground motion was generally more reliable than the single and multi-modal pushover methods considered in that project. Nevertheless, in addition to the MPA, the Consecutive Modal Pushover (CMP, Poursha et al. 2009), was selected for further exploration. Other promising methods reported in the literature (e.g. Aydinoglou 2003, Antoniou and Pinho 2004), were not included for brevity, but also, in many cases, due to their need for specialized software. The NSPs evaluated are briefly summarized below: 
This standard, aimed at the assessment of existing buildings, puts forward a basic pushover procedure. The buildings are "pushed" with a first-mode lateral load pattern until a target displacement is obtained, defined as:

$$
d_{t}=C_{0} C_{1} C_{2} C_{3} S_{a}\left(T_{e}\right) \frac{T_{e}^{2}}{4 \pi^{2}} g
$$

where $C_{0}, C_{1}, C_{2}$ and $C_{3}$ are modification factors, $T_{\mathrm{e}}$ is the effective fundamental period of the building and $S_{a}\left(T_{e}\right)$ is the elastic acceleration response spectrum at $T_{e}$. More specifically, $C_{0}$ is here considered equal to the modal participation factor of the first mode. $C_{1}$ is obtained with the improved ASCE/SEI 41-06 relationship: $C_{1}=1+(R-1) / a T_{e}^{2}$, where $R$ is the strength reduction factor $R=C_{\mathrm{m}} S_{\mathrm{a}} W / F_{\mathrm{y}} \mathrm{g} \geq 1$. In the numerical examples that follow $a=130$ (for site class B) and $C_{m}=M_{n}^{*} / W$ is the first mode modal contribution factor. $C_{3}$ considers the P- $\Delta$ effects and is here taken equal to 1. The coefficient $C_{2}$, takes into consideration the effect of hysteretic behavior and is calculated as $C_{2}=1+(1 / 800)\left((R-1) / T_{e}\right)^{2}$.

Eurocode/N2 method:

The N2 method was initially proposed by Fajfar and Fischinger (1988) and was later expressed in a displacement-acceleration format Fajfar (1999). Recently, the method was included in the Eurocode 8 (2004) standards, while it has been extended to account for higher-mode effects recently by Kreslin and Fajfar (2011). Conceptually, in its typical code-format, it is a variation of the Capacity Spectrum Method that instead of highly-damped spectra uses an $R-C_{1}-T$ relationship. The method, as implemented in Eurocode 8 (EC8), consists of the following steps: (i) Perform pushover analysis and obtain the capacity curve in base-shear versus roof displacement $\left(V_{\mathrm{b}}-u_{r}\right)$ terms, (ii) Convert the pushover curve of the MDOF system to the capacity diagram of an equivalent SDOF system and approximate the capacity curve with an idealized elastic-perfectly plastic relationship to determine the period $T_{e}$ of the equivalent SDOF system, (iii) estimate the displacement of the MDOF system simply as $d_{t}=C_{0} d_{t}^{*}$, where $d_{t}^{*} i s$ the target displacement of the corresponding inelastic SDOF system. Only a first-mode lateral load pattern has been considered. Different expressions are suggested for short and for medium-to-long period ranges, for the latter case $d_{t}^{*}$ is equal to the displacement of the corresponding elastic SDOF system, calculated as:

$$
d_{e t}^{*}=S_{a}\left(T_{e}\right)\left[\frac{T_{e}}{2 \pi}\right]^{2}
$$

\section{Modal Pushover Analysis (MPA):}

This procedure, initially proposed by Chopra and Goel (2002), makes use of two or more pushover curves obtained in separate analyses using load patterns based on the first, second, and possibly third mode. Although subsequently Chopra and Goel (2005) recommended a second analysis phase to de- 
termine member forces, this investigation follows the process more common among practitioners and researchers in which all response quantities are determined in a single application.

The steps of the Modal Pushover Analysis (MPA) method, are summarized as follows: (i) Calculate the natural frequencies, the mode shapes and the lateral load patterns $\mathbf{s}_{i}=\mathbf{m} \boldsymbol{\varphi}_{i}$. (ii) Analyze with only the gravity loads and obtain the corresponding response quantities $r_{\mathrm{g}}$. (iii) For the $i^{\text {th }}$ mode, develop the base shear-roof displacement curve, $V_{b i}-u_{r n}$, using the $\mathbf{s}_{\mathbf{i}}$ distribution of lateral forces. (iv) Idealize the pushover curve as a bilinear curve and compute the target displacement $\delta_{\mathrm{t}}$ for each independent modal analysis using the ASCE/SEI 41-06 $R-C_{1}-T$ relationship. ( $v$ ) From the pushover results (Step iii), extract values $r_{\mathrm{i}+\mathrm{g}}$ of desired response quantities due to the combined effects of gravity and lateral loads. ( $v i$ ) Repeat steps $i i i-v$ for as many modes as required (as discussed in Chopra and Goel 2002), thus 2 modes for the 2-story RCMRF and 3 for the 4- and the 8-story RCMRF buildings. (vii) Compute the dynamic response due to the $i^{\text {th }}$ mode as $r_{i}=r_{i+g}-r_{g}$. Determine the total response (demand) by combining gravity response and the modal responses using the SRSS rule: $r=r_{g}+\left(\Sigma r_{i}^{2}\right)^{1 / 2}$.

\section{Consecutive Modal Pushover (CMP):}

This procedure, initially proposed by Poursha et al. (2009), uses invariant load patterns for up to three modes, applied consecutively in stages in a single pushover analysis. The method would appear to have an advantage over the MPA method in that nonlinear interactions among the modes are explicitly modeled, and capacity limits on demands (e.g. shear forces in hinging beams) are inherently represented in the analyses. Gravity loads are applied prior to the application of the quasi-first mode load pattern. In this approach, $(i)$ interaction of multiple modes is considered in a way that may cause different inelastic mechanisms to form, and (ii) the member forces resulting from the analysis are consistent with member capacity limits (e.g. beam shears do not exceed the shears associated with development of a plastic mechanism).

The CMP considers up to three modes, applied consecutively in stages in a single pushover analysis. In this way, it may come closer to representing the higher mode responses that take place when the peak displacement response is realized dynamically. The first stage of the pushover analysis uses a quasi-first mode load pattern, consisting of an inverted triangular load pattern for medium-rise buildings and a uniform load pattern for high-rise buildings. The second stage consists of a sequence of quasi-first and second mode forces. The quasi-first mode forces are applied until the roof displacement equals $a_{1} \delta_{\mathrm{t}}$, where $a_{1}$ is the modal contribution factor of the first mode and $\delta_{\mathrm{t}}$ is the target displacement determined for the first mode. Upon reaching $a_{1} \delta_{t}$, incremental forces are applied that follow a second mode pattern. The incremental displacement used for this analysis stage is $\left(1-a_{1}\right) \delta_{\mathrm{t}}$. The third stage, required only for buildings with fundamental periods of 2.2 seconds or higher, con- 
sists of a sequence of quasi-first, second, and third mode forces. As before, the quasi-first mode forces are applied until the roof displacement equals $a_{1} \delta_{\mathrm{t}}$. Upon reaching $a_{1} \delta_{\mathrm{t}}$, incremental forces are applied that follow a second-mode pattern until the roof displacement increases by $a_{2} \delta_{\mathrm{t}}$. At this point, incremental forces that follow a third-mode pattern are applied until the roof displacement increases by $\left(1-a_{1}-a_{2}\right) \delta_{\text {t. }}$. After the last step of each separate stage is completed, the peak value of any EDP of interest is retained and the final EDP estimate is obtained from the maximum value of the three stages.

\section{Modal Response Spectrum Analysis (MRSA):}

When applied to structures in the nonlinear range of response, Modal Response Spectrum Analysis (MRSA) relies on simple extrapolations of linear behavior and thus approximately represents the equal displacement rule for deformation-related quantities. The demands are calculated performing linear-elastic analysis using lateral load patterns proportional to the modes of vibration, which are similar to those of the MPA procedure. For the numerical study that follows, the target displacements were calculated using the $C_{1}$ and $C_{2}$ relationships of ASCE/SEI 41-06, while $C_{3}$ was taken equal to 1.0. The EDP values obtained using every mode-proportional lateral load pattern are then combined with the SRSS rule to obtain the final response estimates.

\section{BUILDING MODELS}

The structural systems considered are a two-story, a four-story and an eight-story reinforced concrete moment resisting frame (RCMRF) building, originally designed as "archetype" buildings in FEMA P695 (2009). All three buildings have three bays and are completely regular and symmetric. A generic description of the three buildings is shown in Figure 1. All buildings have bay width $9.1 \mathrm{~m}$ (30ft) and story heights $4.6 \mathrm{~m}$ (15ft) for the first story and $4.0 \mathrm{~m}(13 \mathrm{ft})$ for the stories above. The three buildings form a simple basic test for the static pushover methods. For such low- and mid-rise structures NSP's are expected to perform well, especially in the in the near post-nominal-yield region.

The buildings were designed as special RC moment frames following the provisions of the 2003 IBC (IBC 2002). Beam sizes were determined by minimum size requirements. Column strengths were determined to follow strong-column-weak-beam requirements, reflected in required column-tobeam flexural strength ratios and joint shear requirements. The selection of the beam stirrups was controlled by shear capacity design, while the column transverse reinforcement was based on confinement requirements. The design of the frames is described in FEMA P695 (2009). 


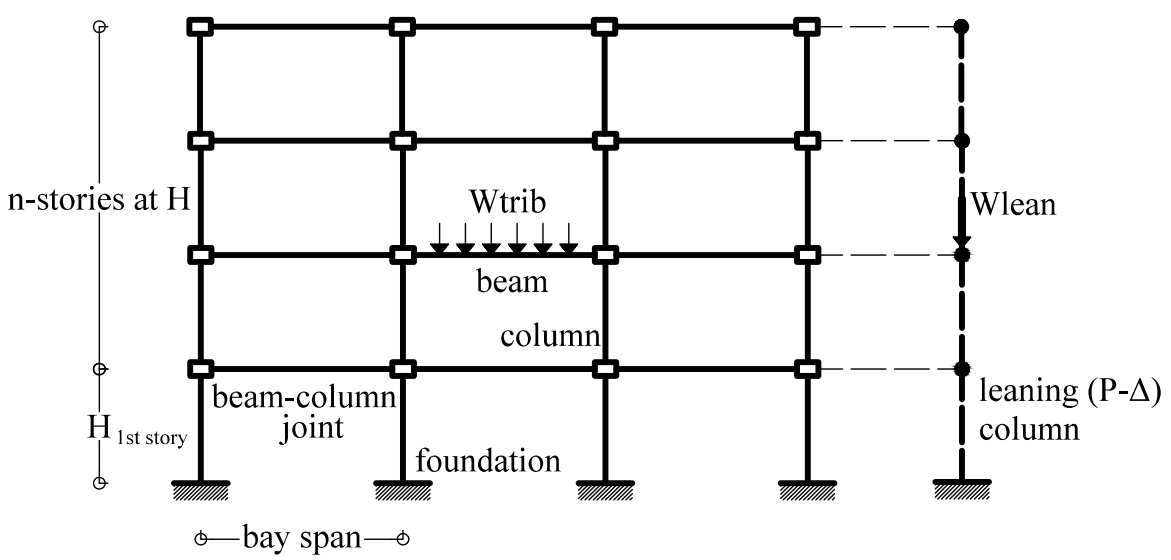

Figure 1 Generic description of the three RC moment resisting frame buildings (reproduced from Haselton and Deierlein 2007).

Models of the buildings were created for structural analysis. Planar 2D models were used, incorporating one-dimensional line-type elements, as discussed in FEMA P695. Component models simulated the nonlinear degrading response of beams, columns and joints. The hysteretic model used for modeling the cyclic behavior in NRHA is the "bilin" material available in the OpenSees software platform (McKenna and Fenves 2001). This is a peak-oriented model with a piecewise linear envelope that is able to incorporate stiffness and strength degradation. According to Haselton and Deierlein (2007) and Haselton et al. (2011) the model consists of three branches, an initial elastic branch, a strain hardening branch, and a descending branch that terminates at an ultimate chord rotation equal to 0.1 radians. This ultimate rotation value is considered to be conservative given the paucity of test data (Haselton et al. 2011). The load combination used to represent gravity loads was 1.05(Dead) + 0.25(Live); the gravity load was considered to remain constant throughout the loading history. The flexural strengths of the members were based on calibration with test data from columns and beams with low-to-moderate axial load and ductile detailing. The analytical models do not have the capability to represent shear failure, meaning that the shear capacities and shear failure modes are not represented in the structural models. More details about the models can be found in FEMA P-695, Haselton et al. (2011) and Lignos and Krawinkler (2009). No post-simulation evaluation of potential shear failure modes was made. This mode of failure is not expected for such well-behaved capacitydesigned buildings, and probably is not expected even close to collapse (Haselton and Deierlein 2007).

Tributary gravity loads act on seismic framing. In addition, a "leaning column" is used to capture P-Delta effects caused by the gravity load acting on the internal gravity frames. Rayleigh damping in the $1^{\text {st }}$ and $3^{\text {rd }}$ mode of vibration was set equal to approximately $5 \%$ of critical damping. The resulting first mode periods of the 2-, 4-, and 8-story frames were $0.625,0.855$, and $1.80 \mathrm{sec}$, respectively. 


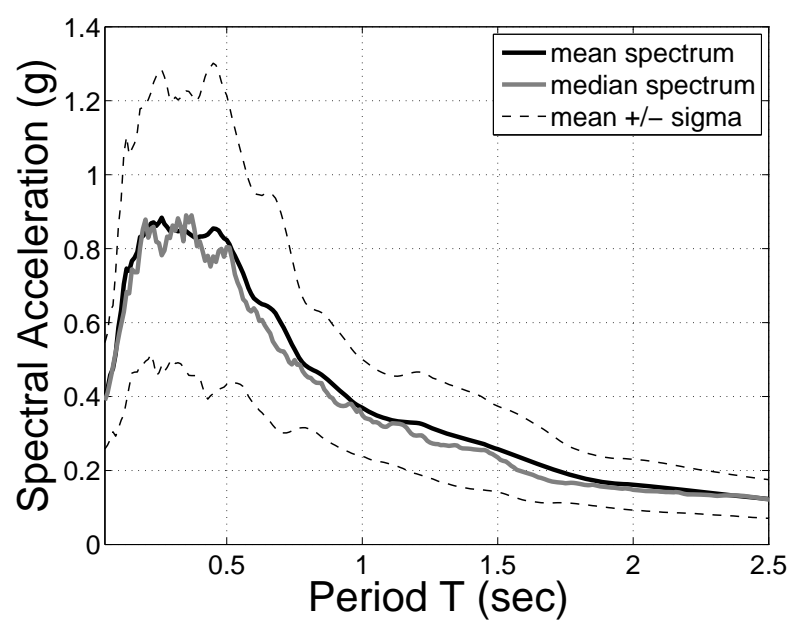

Figure 2 Mean and median response spectra of the ground motion set considered.

\section{GROUND MOTIONS}

Nonlinear response history analysis was performed using the suite of 22 pairs of orthogonal horizontal ground components (for a total of 44 records) that comprised the FEMA P-695 far-field data set. A fairly elaborate scheme was devised in FEMA P-695 to ensure the suite of records contains a realistic level of record-to-record dispersion. In short, the orthogonal ground motions are normalized according to PGVpeer, as discussed in FEMA P-695. PGVpeer is the geometric mean (square root of the product) peak ground velocity (PGV) of two orthogonal components considering different record orientations. The PGVpeer values adopted were taken directly from the PEER NGA database. All ground motions are far-field recordings and they are applied in their recorded orientations. The 22 pairs of ground motions are first scaled so that their PGVpeer values match the median PGVpeer value of the whole set of unscaled records. The records were further scaled using scale factors (SFs) equal to $0.5,1$ and 2 . These scale factors result in median elastic response spectra that correspond to ground motion at a Los Angeles, California site with mean recurrence intervals of approximately 100, 400, and 2475 years, respectively. Each record of the scaled pair is applied independently in a planar analysis.

\section{NUMERICAL RESULTS}

A series of numerical results comparing the performance of the different NSP methods follows. The comparison is performed with respect to the peak values of different engineering demand parameters (EDP). The term 'peak' denotes the maximum value of the EDP over the entire response history. The EDPs considered include both displacement and force-based quantities; intermediatelevel EDPs (e.g. drifts) are emphasized over component-level quantities (e.g. chord rotations). This is done because intermediate-level EDPs correlate well to component-level quantities, but are less sensitive to the fine details of the component models, and thus may serve as global damage indicators. The relationship between intermediate and component-level EDPs is examined further in the ATC- 
76-6 report (Appendix B) (NIST 2010). Therefore, the EDPs presented here are peak values of: story displacement, story drift ratio, story shear force and story overturning moment. The peak story drift ratio is defined as the maximum of the absolute value of the difference of the horizontal displacement of adjacent stories over time, normalized by the height of the story.

\section{Nonlinear Response History Analysis}

Figure 3 and Figure 4 present selected results from nonlinear response history analysis (NRHA). The curves shown correspond to story-wise profiles of the median response quantities plotted for each of the three scale factors. The results for these structures indicate:

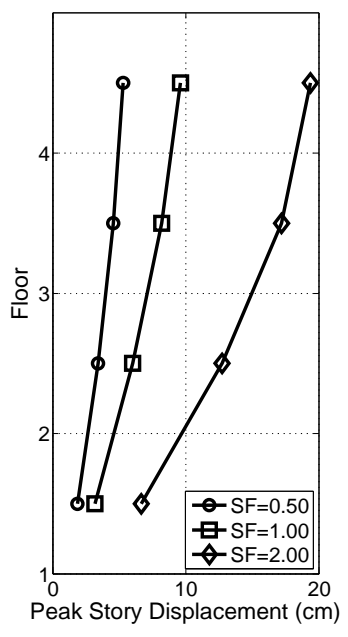

(a)

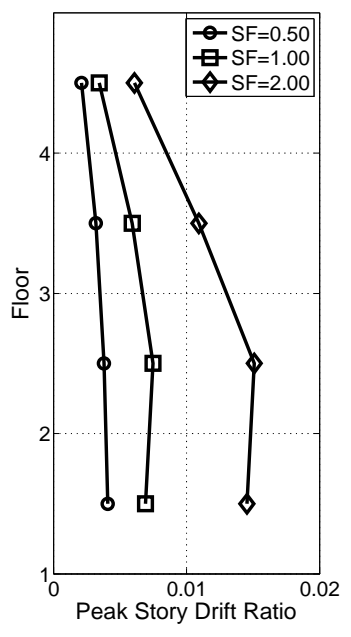

(b)

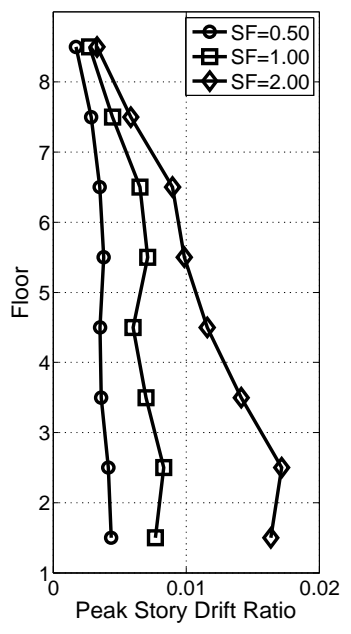

(c)

Figure 3 NRHA profiles of: (a) peak story displacement (4-Story), (b) peak story drift (4-Story), and (c) peak story drift (8-Story).

- The maximum of the median peak floor displacements over the height of the frames typically appears at the top story (Figure 3a).

- The median of peak story drift demands, is highest at the lower stories (usually at the second story) and lowest at the top story, for these regular frames (Figure 3b,c).

- According to Figure 4, median peak story shears do not follow the lateral load pattern used to design the structure. The median peak story shears also do not follow the pattern resulting from lateral forces applied in a first-mode based pushover analysis. Median peak story shears in the upper stories are significantly larger than would be expected from these load patterns. Median peak story shears in the upper stories increase disproportionately with an increase in scale factor.

- Median peak overturning moments tend to follow the concave pattern associated with the lateral load patterns used in design or first-mode pushover analysis (Figure 4c).

- Median peak story shears and overturning moments tend to "saturate" as the scale factor increases. This reflects limits on demand associated with reaching the maximum moment capacity in the component models (Figure 4). 


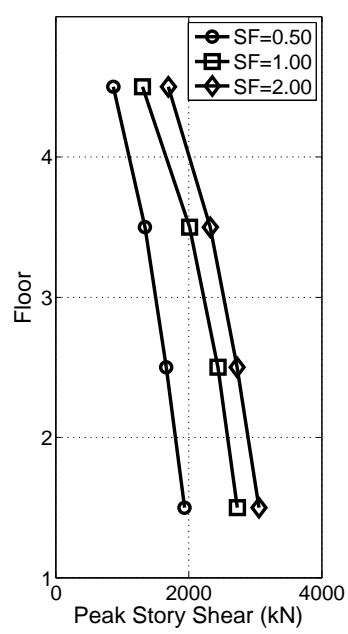

(a)

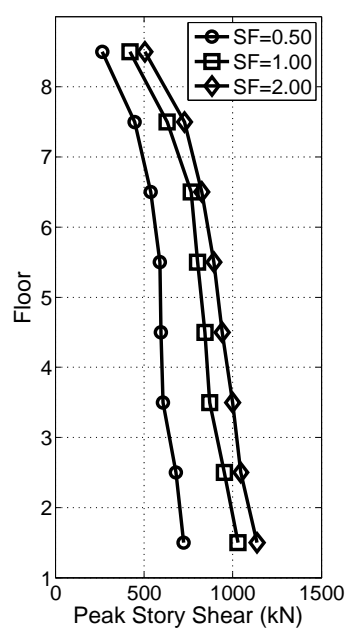

(b)

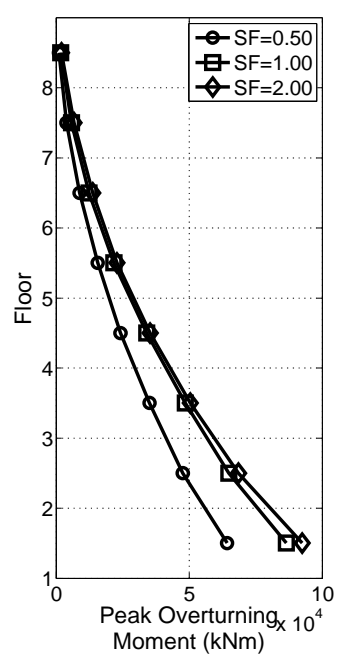

(c)

Figure 4 NRHA profiles of: (a) peak story shear (4-Story), (b) peak story shear (8-Story), and (c) peak overturning moment (8-Story).

The above observations suggest that a single static analysis cannot both represent median peak overturning moments, which tend to follow the pattern obtainable in a first mode pushover analysis, and median peak story shears, which deviate significantly from readily obtainable patterns. Moreover, higher modes appear to have an appreciable effect on story drift and story shears, but not floor displacements or overturning moments, as discussed in reference (Aschheim et al. 2007). Figure 3 and Figure 4 display curviness in the drift and the shear profiles in the mid-height stories, showing apparent departure from a first-mode dominated response even for these regular frames.

Since this is a practice-oriented study, we choose not to provide exact height-wise dispersion values. However, average dispersion values are 0.3-0.4 for peak story displacements, $0.25-0.45$ for peak story drift ratio, 0.05-0.30 for peak story shears and 0.10-0.25 for peak overturning moments. As dispersion we define the standard deviation of the natural logarithms of the height-wise EDP values.

\section{Single Mode Nonlinear Static Analysis}

Figure 5 shows the capacity curves obtained in first, second and third mode pushover analyses of the three RC moment frames. Also shown on this figure are the target displacements determined using the formulas of ASCE/SEI 41-06 and the N2 method of Eurocode 8. Target displacements were determined using the mean elastic response spectrum of the 44 normalized records, scaled by the relevant scale factor. Roof displacements at yield are observed to occur at target displacements about 0.5 to $0.6 \%$ of the building's height. Both methods produce nearly identical target displacement estimates for the three moment frames; for this reason, only the ASCE-41 target displacements were used to estimate response quantities in subsequent first mode analyses. Target displacements for a scale factor of 0.5 are in the elastic regime, those for the records scaled by 1.0 are nearly elastic, and those for a scale factor of 2.0 cause moderate inelastic response, developing system ductilities of 2- 
3, when viewed from a first-mode pushover perspective. Target displacement estimation may introduce additional error on the results of NSPs. In our case, the nearly perfect bilinear shape of the firstmode capacity curves (Figure 5) resulted in insignificant mean errors (Appendix E, NIST 2010).

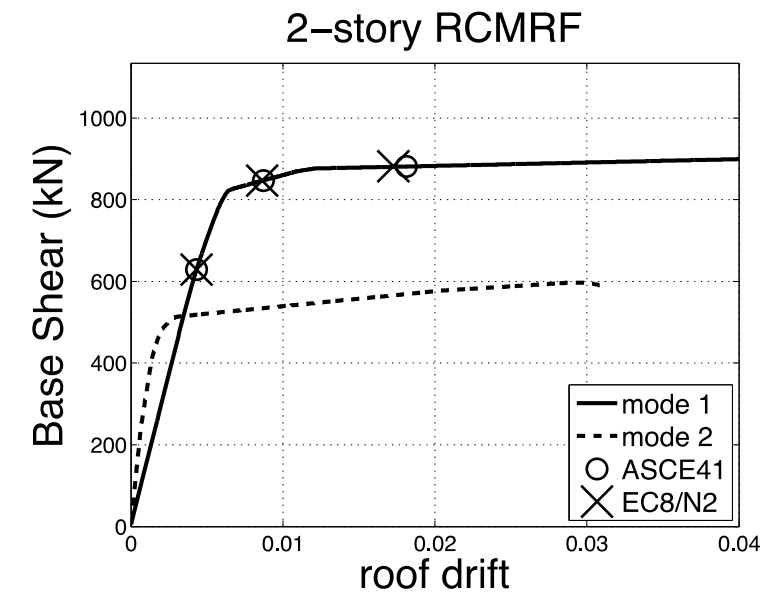

(a)

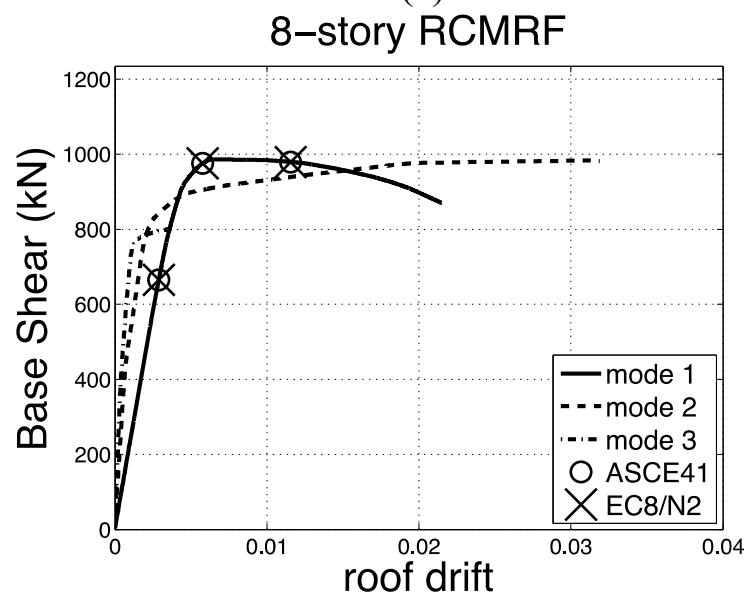

(c)

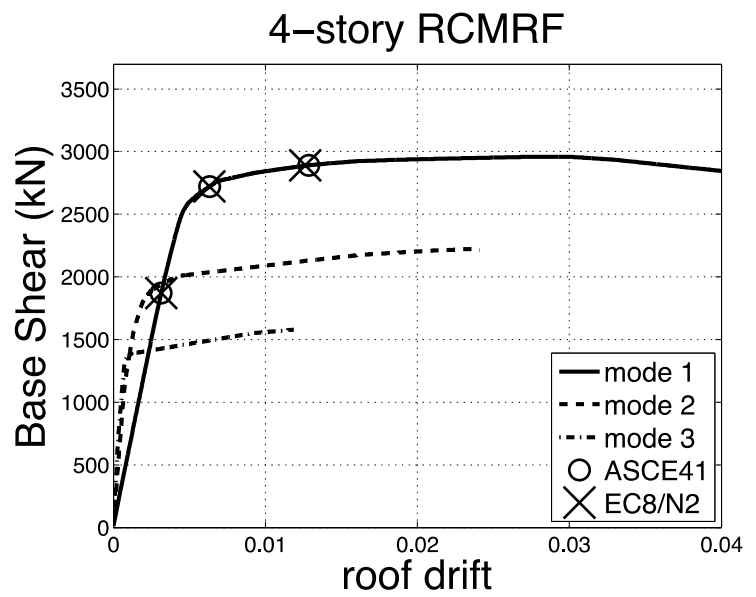

(b)

Figure 5 Static pushover curves and target displacement estimates for the 2-, 4-, and 8-story RCMRFs, for ground motion scale factors of 0.5, 1.0, and 2.0. ASCE-41 and N2/EC8 methods produce nearly coincident target displacement estimates.

Figure 6 and Figure 7 show the ratios of estimates from the pushover analyses and the medians from NRHA over the height of each frame for scale factors of 0.5 and 2.0, respectively. The estimates are reasonably accurate for all three EDPs for the 2-story RCMRF, for which the error is less than $20 \%$ (relative to the NRHA median). For the 4-story frame, the accuracy of estimates of story drifts, story shears and overturning moments degraded as the scale factor increased from 0.5 to 2.0. This is attributed to the tendency of equivalent SDOF systems to overestimate peak displacements of MDOF systems with increasing severity of nonlinear response, as has been recognized previously. This tendency for ASCE-41 target displacements to overestimate actual MDOF response with increasing inelasticity and increasing numbers of stories is subtly apparent in Figure 7. The degradation in accuracy with increase in scale factor was small for story shears and overturning moments and greater for the drift profiles. The accuracy of NSP estimates also degraded with increase in scale fac- 
tor for the 8-story frame, where the error in the story shears and overturning moments of the top stories was on the order of $60 \%$. Peak story drifts were grossly underestimated at the top stories and overestimated at the bottom stories at higher scale factors. This is attributed to the constant shape of the lateral loading scheme.

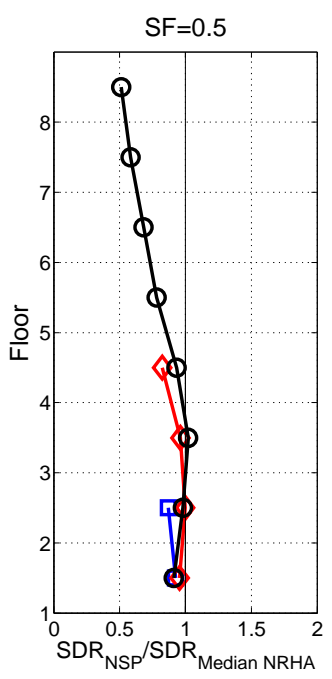

(a)

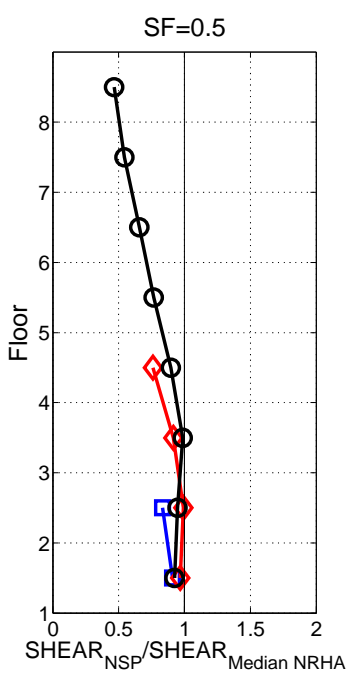

(b)

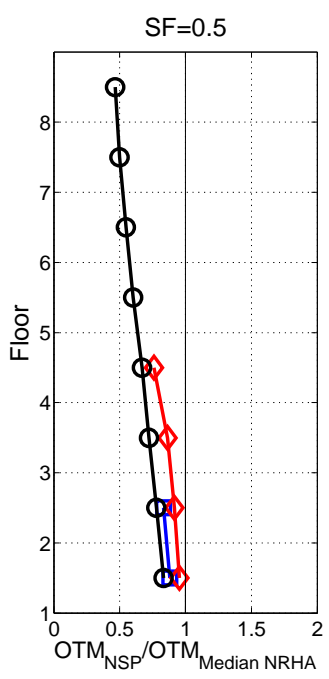

(c)

Figure 6 All buildings: ratios of ASCE-41 NSP and NRHA. (a) peak story drifts $(\mathrm{SF}=0.5)$, (b) peak story shears $(\mathrm{SF}=0.5)$, and $(\mathrm{c})$ peak overturning moments $(\mathrm{SF}=0.5)$.

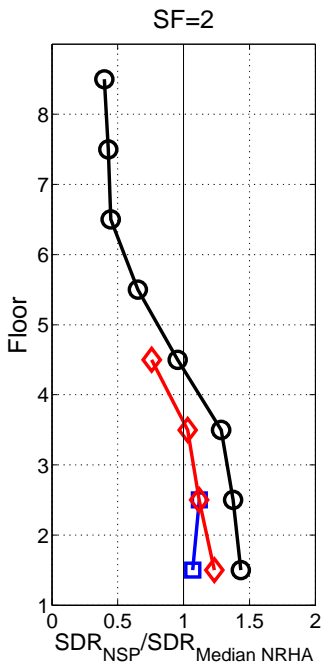

(a)

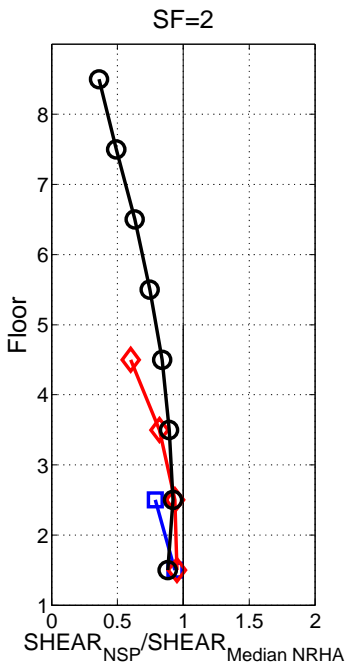

(b)

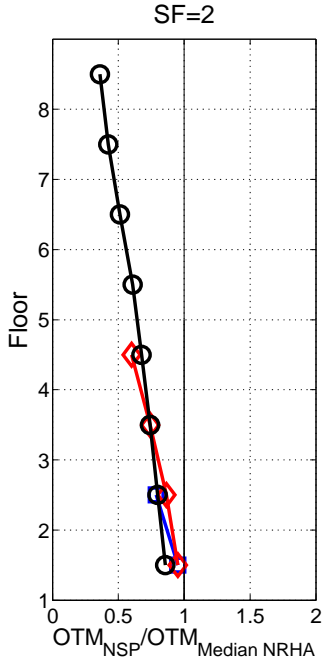

(c)

Figure 7 All buildings: ratios of ASCE-41 NSP and NRHA. (a) peak story drifts (SF=2.0), (b) peak story shears $(\mathrm{SF}=2.0)$, and $(\mathrm{c})$ peak overturning moments $(\mathrm{SF}=2.0)$.

\section{Modal Pushover Analysis}

Target displacements for higher modes were determined using the coefficients provided in ASCE/SEI 41-06 and the N2 method of Eurocode 8 applied to the scaled mean elastic response spectrum. The capacity curves are shown in Figure 5. Target displacements for modes other than the first are not shown, since they all lie in the elastic range, where both methods produce identical displacement estimates. As noted earlier, SRSS combinations were taken of the individual modal contribu- 
tions for every response quantity of interest.

Selected results for the three buildings are shown in Figure 8-Figure 10. In addition to the MPA estimates, the peak responses for the individual records and their mean and mean \pm one standard deviation values are also presented. Furthermore, ratios of NSP estimated values and NRHA medians are plotted over the height of each frame in Figure 11 and Figure 12 at scale factors of 0.5 and 2.0, respectively. Note that when only the first-mode is considered the results coincide with those of the ASCE/SEI 41-06 method.

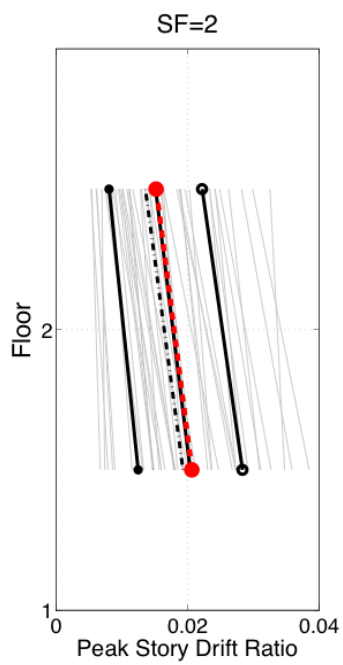

(a)

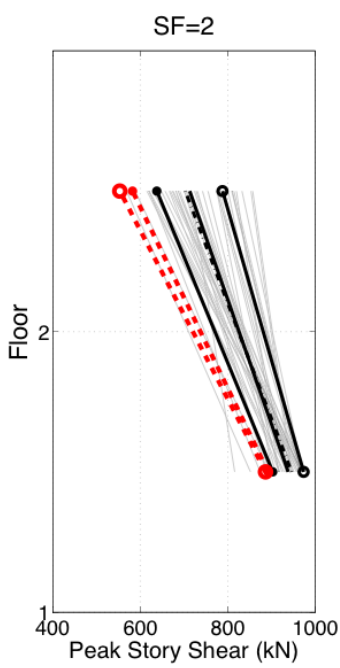

(b)

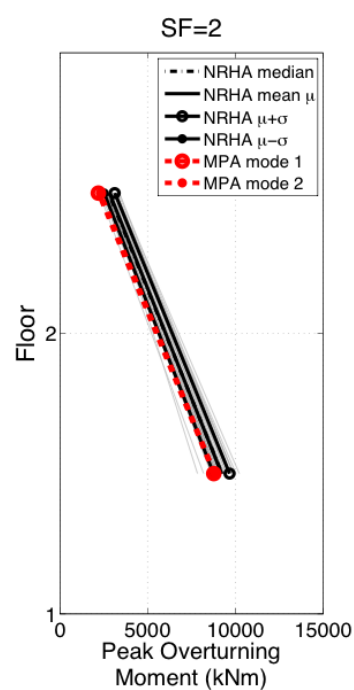

(c)

Figure 8 2-story RCMRF: profiles of (a) peak story drift $(\mathrm{SF}=2),(\mathrm{b})$ of peak story shears $(\mathrm{SF}=2)$, and (c) peak overturning moments $(\mathrm{SF}=2)$.

For the 2-story frame, second-mode contributions to story drifts, and overturning moments were negligible and reasonably accurate estimates of these quantities were obtained with the first mode estimates (Figure 8). While story shears were estimated accurately for a scale factor of 0.5 (Figure 6a, Figure 8a), the inclusion of second-mode contributions in the MPA procedure did not sufficiently increase the story shears to result in an accurate estimate at a scale factor of 2.0 (Figure $8 \mathrm{~b}$ ). This suggests a relatively severe constraint on the reliable application of both single mode and simple multimodal pushover methods. 


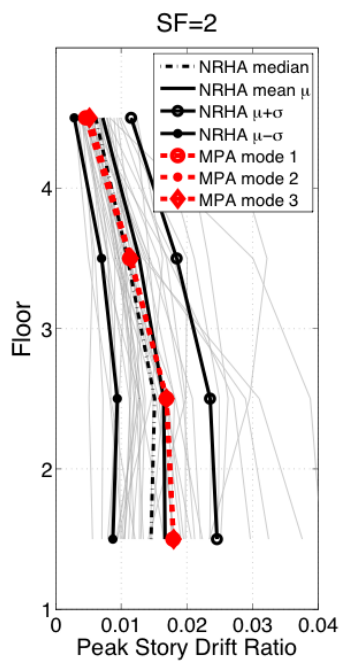

(a)

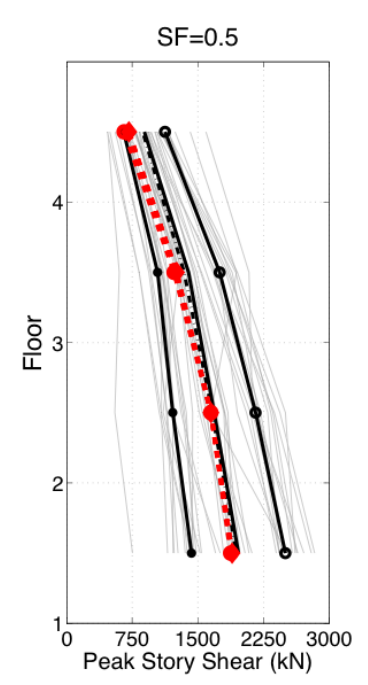

(b)

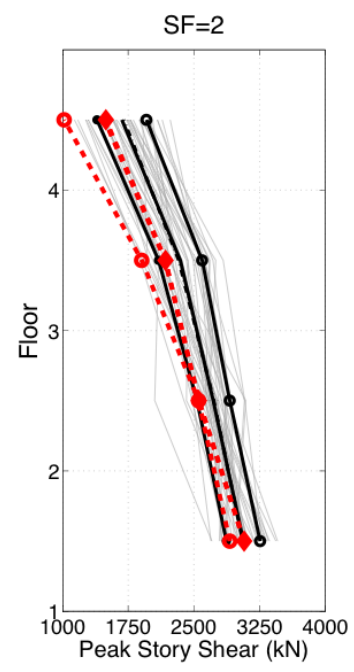

(c)

Figure 9 4-story: profiles of (a) peak story drift $(\mathrm{SF}=2)$, (a) peak story drift $(\mathrm{SF}=0.5)$, (b) peak story shears $(\mathrm{SF}=2)$.

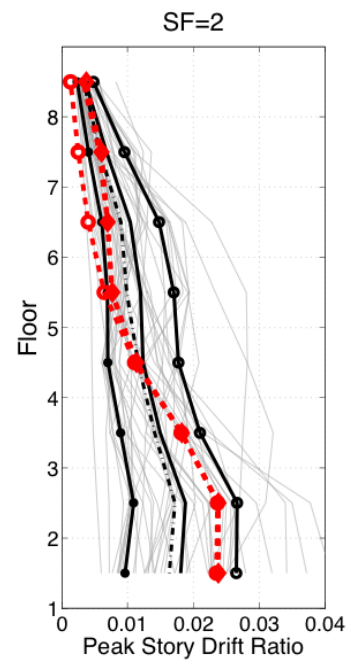

(a)

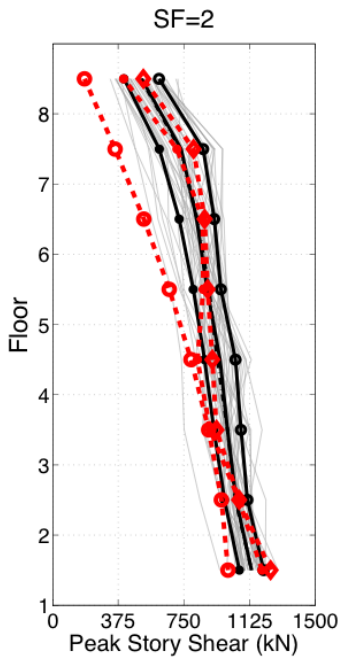

(b)

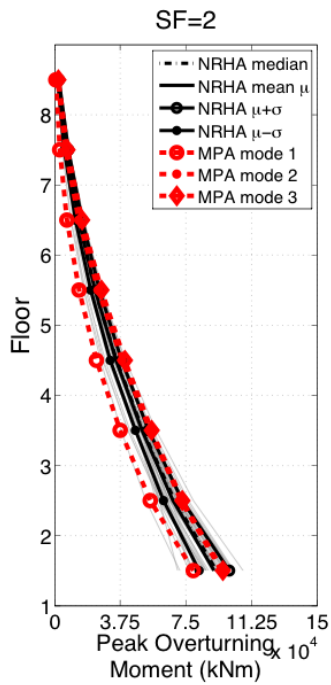

(c)

Figure 10 8-story, profiles of: (a) peak story drift $(\mathrm{SF}=2.0)$, (b) peak story shears $(\mathrm{SF}=2)$, and (c) peak overturning moments $(\mathrm{SF}=2)$.

For the 8-story frame, second-mode contributions to story drift were not negligible and improved the story drift estimates, but accuracy varied with location and scale factor (Figure 10). Moreover, as shown in Figure 11 and Figure 12, the accuracy of story drift estimates improved with an increase in scale factor at the upper stories, while story drift estimates became less accurate as the scale factor increased at the lower stories. The overestimation observed at the lower stories is attributed to the constant shape of the lateral load pattern. As for story drifts, the accuracy of story shear estimates varied with location and scale factor. Both second- and third-mode contributions to story shears were appreciable. At the lower stories, story shear estimates were most accurate at a scale factor of 0.5 (Figure 11); an increase in scale factor led to significant overestimates (Figure 12). In contrast, at the upper stories, the story shears were underestimated at a scale factor of 0.5 , were estimated with reasonable accuracy at a scale factor of 1.0 (not shown), and were significantly overestimated at a scale 
factor of 2.0. Second mode contributions to overturning moments were not negligible and improved the estimates; overturning moments tended to be underestimated at a scale factor of 0.5 , and were overestimated at a scale factor of 2.0 .

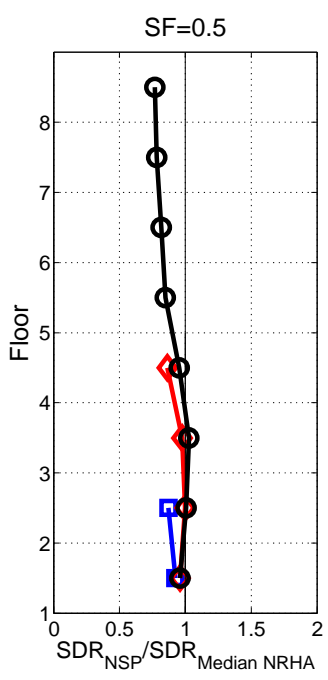

(a)

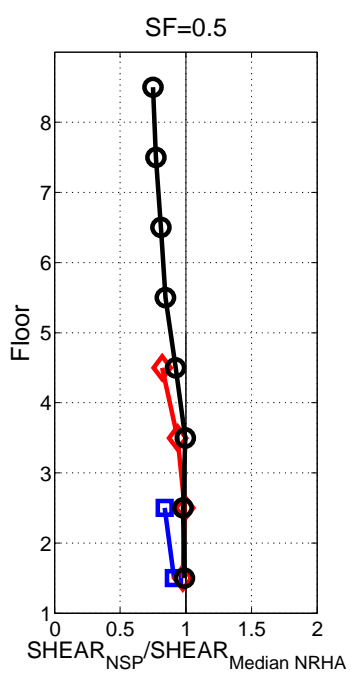

(b)

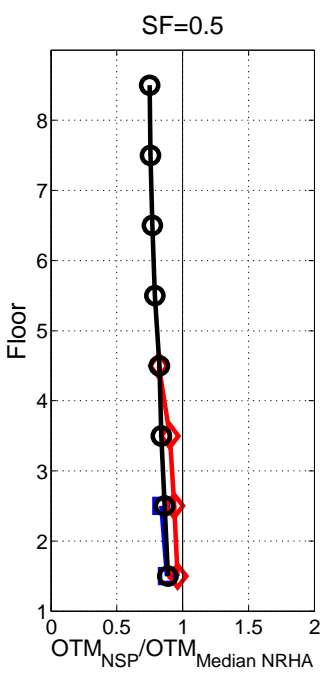

(c)

Figure 11 All buildings: ratio of MPA and NRHA. (a) peak story drifts $(\mathrm{SF}=0.5)$, (b) peak story shears $(\mathrm{SF}=0.5)$, and $(\mathrm{c})$ peak overturning moments $(\mathrm{SF}=0.5)$.

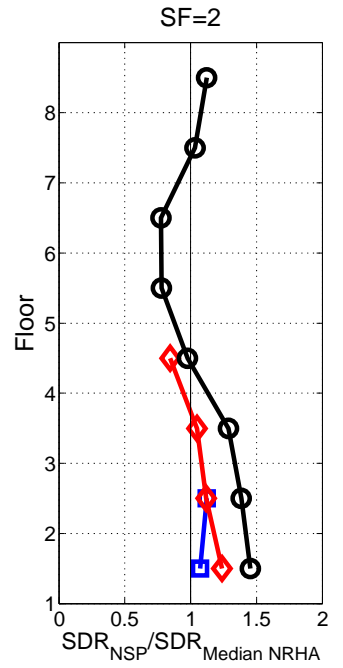

(a)

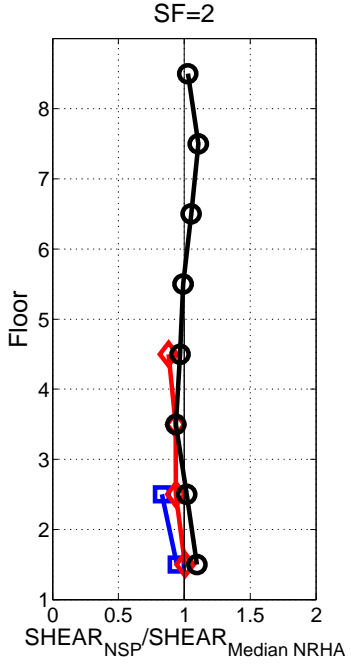

(b)

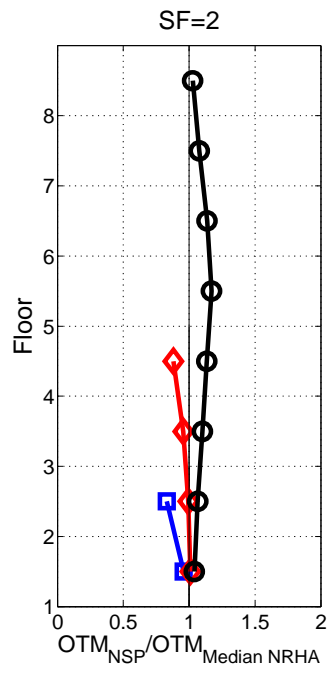

(c)

Figure 12 All buildings: ratio of MPA results and NRHA. (a) peak story drifts ( $\mathrm{SF}=2.0)$, (b) peak story shears $(\mathrm{SF}=2.0)$, and $(\mathrm{c})$ peak overturning moments $(\mathrm{SF}=2.0)$.

\section{Consecutive Modal Pushover}

Selected results obtained by application of Consecutive Modal Pushover (CMP) analysis to the three RCMRFs are shown in igure 13 to Figure 16. In addition to the single-record and NRHA curves, the figures also show with dashed lines the profiles of the two CMP stages and with solid line their envelope. Ratios of estimated values and NRHA medians are also plotted. 


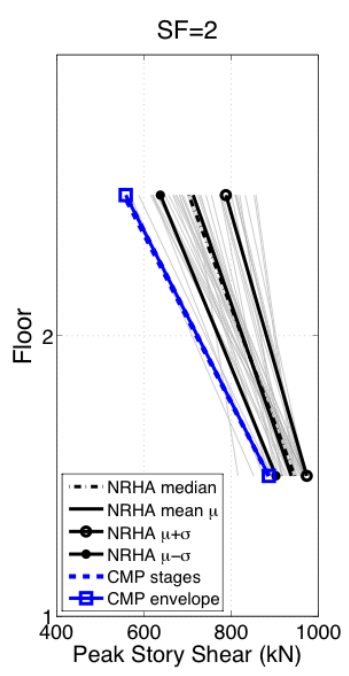

(a)

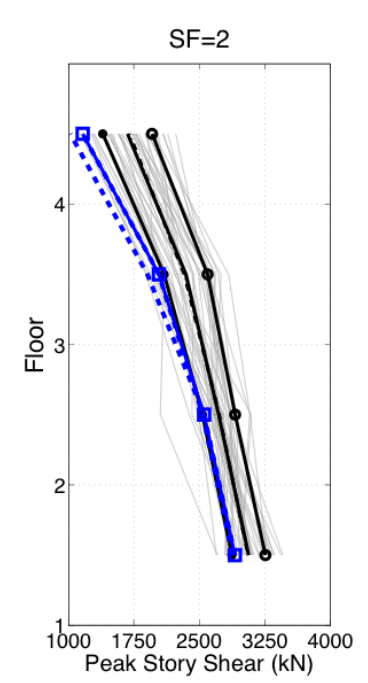

(b)

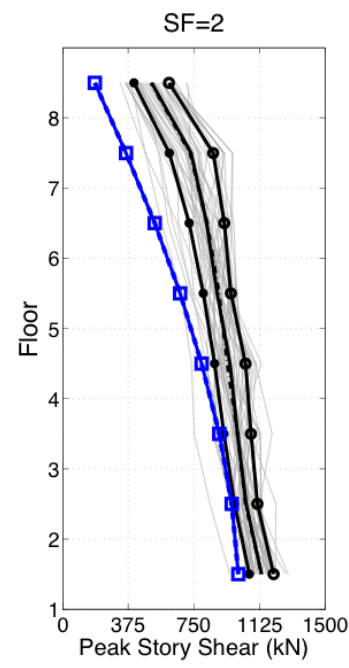

(c)

igure 13 Peak story shears obtained with the Consecutive Modal Pushover method: (a) 2-story $(\mathrm{SF}=2)$, (b) 4-story $(\mathrm{SF}=2)$, (a) 8-story $(\mathrm{SF}=2)$.

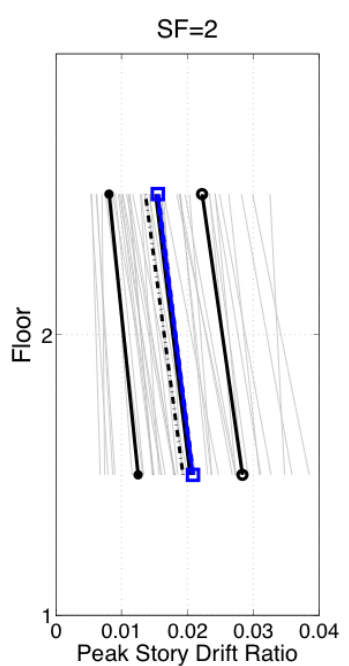

(a)

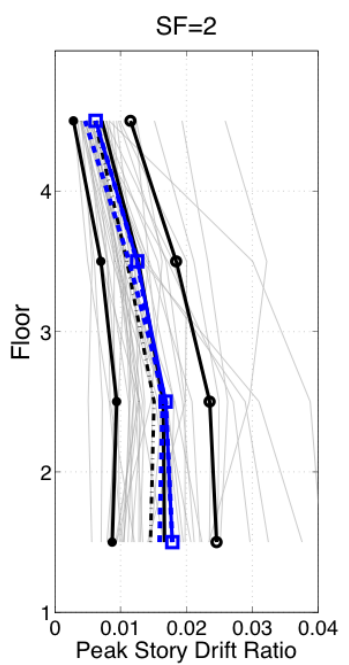

(b)

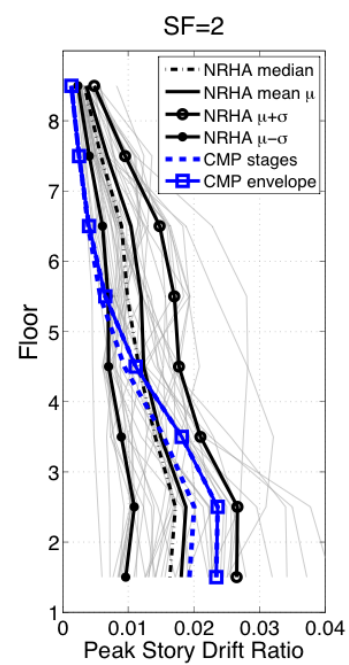

(c)

Figure 14 Peak drift profiles obtained with the Consecutive Modal Pushover method: (a) 2-story RCMRF (SF=2), (b) 4-story RCMRF ( $\mathrm{SF}=2$ ), (a) 8-story RCMRF ( $\mathrm{SF}=2)$.

For the 2-story frame, story drifts were estimated with reasonable accuracy (Figure 15a). Story shears were significantly overestimated at a scale factor of 0.5 (Figure 15b), and significantly underestimated at a scale factor of 2.0 (igure 13a and Figure 16b). For the 4-story frame, the accuracy of estimates of story drift, story shear, and overturning moments varied with location and scale factor. For example, while story drifts at the upper stories were overestimated at a scale factor of 0.5 (Figure 15a), relatively accurate estimates of story drift were obtained over the height of the building at higher scale factors (Figure 14b and Figure 16a). As well, story shears in the upper stories were significantly overestimated at a scale factor of 0.5 (Figure 15b), and story shears over the height of the building were significantly underestimated at a scale factor of 2.0 (igure 13b, Figure 16b). 


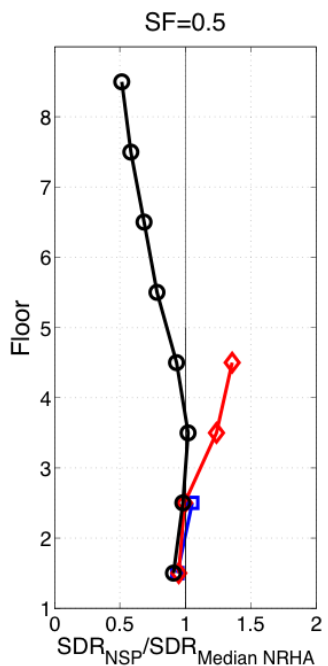

(a)

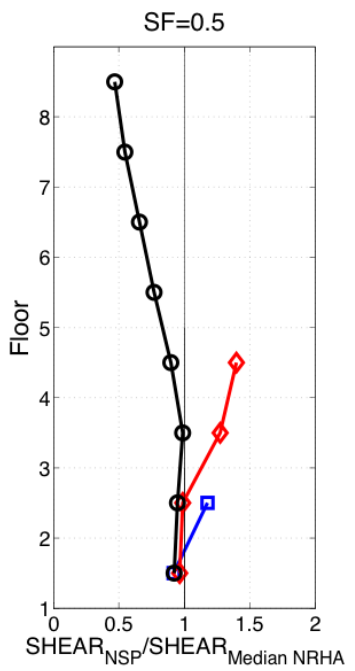

(b)

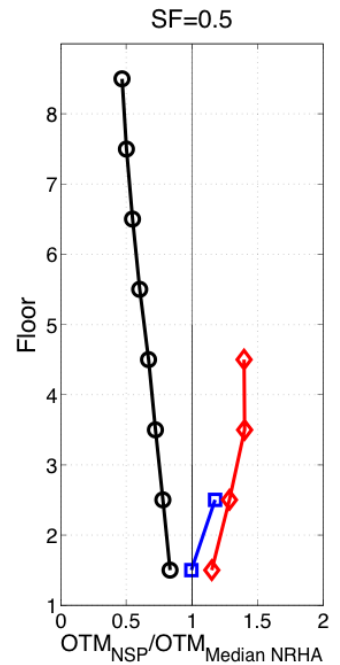

(c)

Figure 15 All buildings: ratio of CMP and NRHA. (a) peak story drifts $(\mathrm{SF}=0.5)$, (b) peak story shears $(\mathrm{SF}=0.5)$, and $(\mathrm{c})$ peak overturning moments $(\mathrm{SF}=0.5)$.

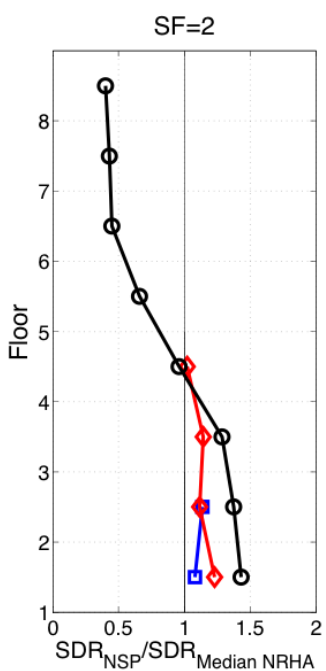

(a)

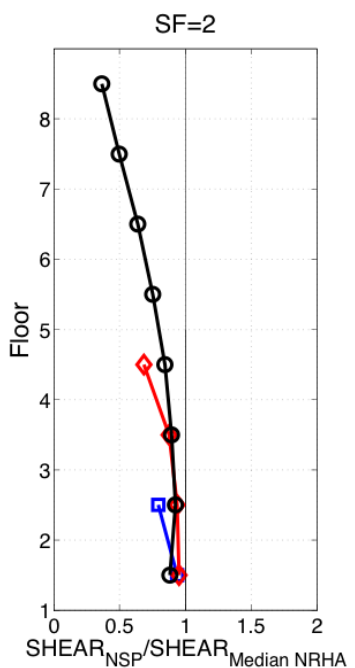

(b)

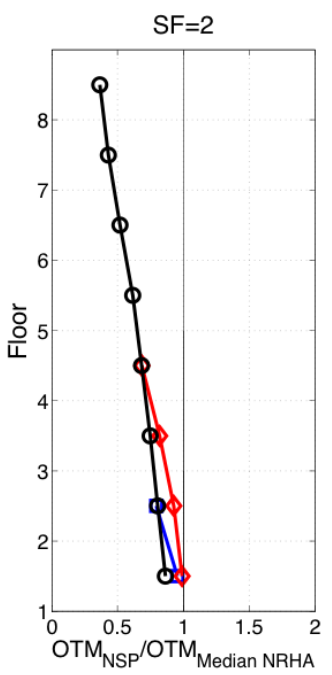

(c)

Figure 16 All buildings: ratio of CMP and NRHA. (a) peak story drifts ( $\mathrm{SF}=2.0$ ), (b) peak story shears $(\mathrm{SF}=2.0)$, and $(\mathrm{c})$ peak overturning moments $(\mathrm{SF}=2.0)$.

For the 8-story frame, peak displacements were overestimated at a scale factor of 2.0 (Figure 16a), just as occurred with the first mode and multiple mode pushover analyses. As for the 4-story frame, the accuracy of estimates of story drift, story shear, and floor overturning moments varied with location and scale factor. Although these results were not especially promising, the authors speculate that a revised version of the CMP might be developed in which loading is applied using sequential modes, considering permutations in the signs of the modes and possibly considering adaptive load vectors.

\section{Elastic Modal Response Spectrum Analysis}

Estimates of response quantities were also made by elastic modal response spectrum analysis using SRSS combinations of the modal values made on the basis of linear elastic response extrapolated to 
the spectral accelerations obtained using scale factors of $0.5,1.0$, and 2.0. Thus, peak floor and roof displacements represent the "equal displacement rule", with drift profiles being proportional to the elastic distributions. Where drift patterns obtained in modal pushover analyses resemble the elastic distributions, displacement and story drift estimates made using elastic modal response spectrum analysis will resemble those obtained with modal pushover analysis, given consistent target displacements (e.g. obtained using the equal displacement rule). Story shear and overturning moment distributions at low scale factors will also resemble those obtained with modal pushover analysis. Of course, at high scale factors, these force-related quantities will be significantly overestimated by the elastic method.

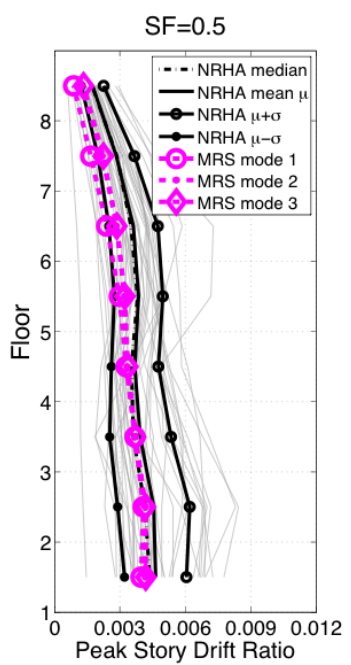

(a)

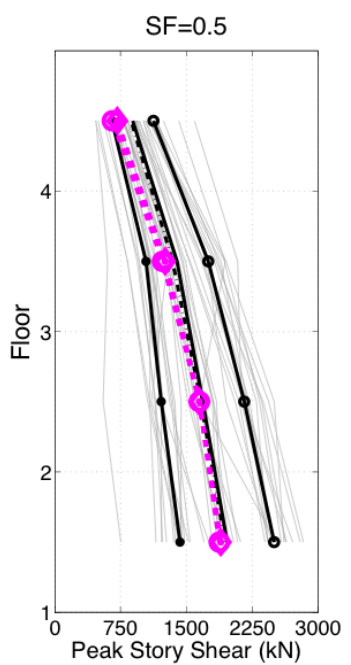

(b)

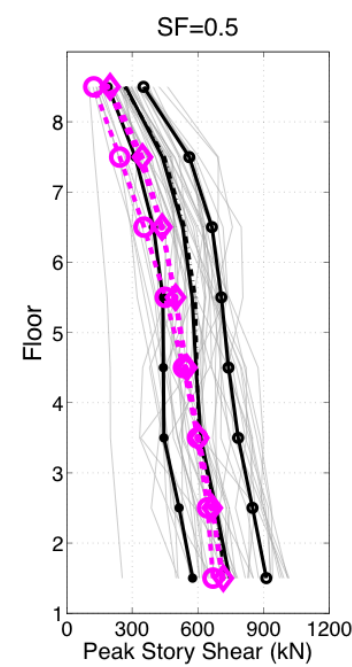

(c)

Figure 17 Selected results for the Modal Response Spectrum Analysis method: (a) 8-story peak story drift $(\mathrm{SF}=0.5),(\mathrm{b}) 4$-story peak story shear $(\mathrm{SF}=0.5)$, and (c) 8 -story peak story shear $(\mathrm{SF}=0.5)$.

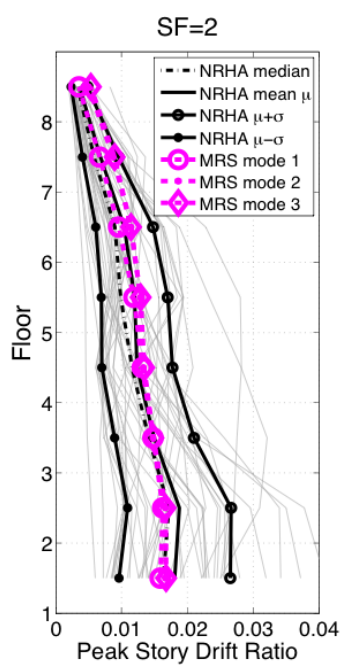

(a)

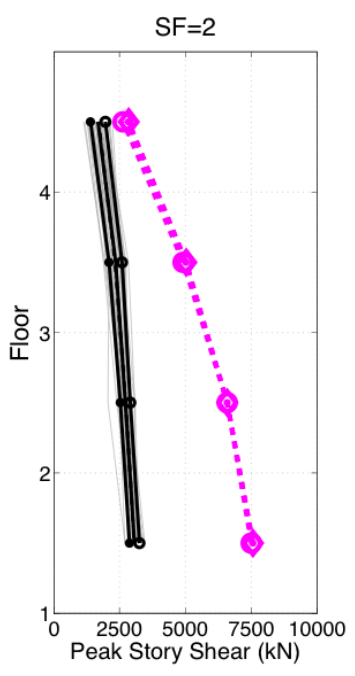

(b)

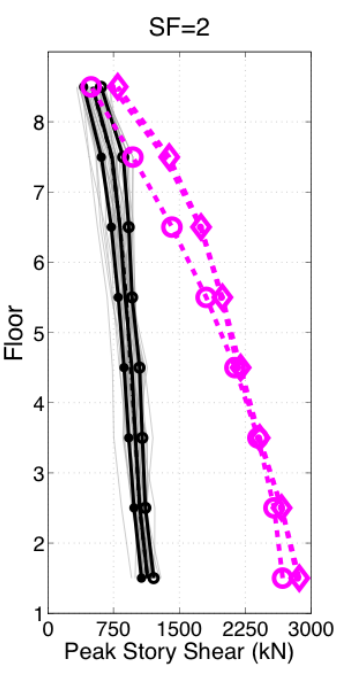

(c)

Figure 18 Selected results for the Modal Response Spectrum Analysis method: (a) 8-story peak story drift $(\mathrm{SF}=2.0)$, (b) 4-story peak story shear $(\mathrm{SF}=2.0)$ and (c) 8-story peak story shear $(\mathrm{SF}=2.0)$. 


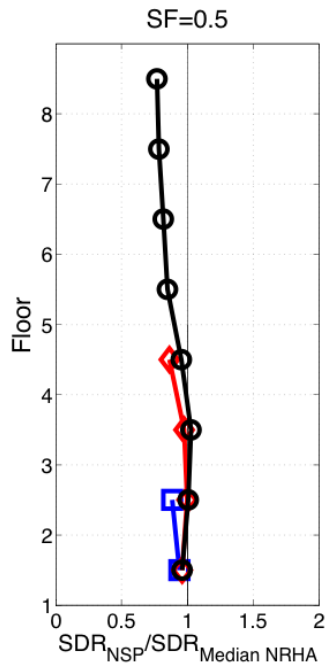

(a)

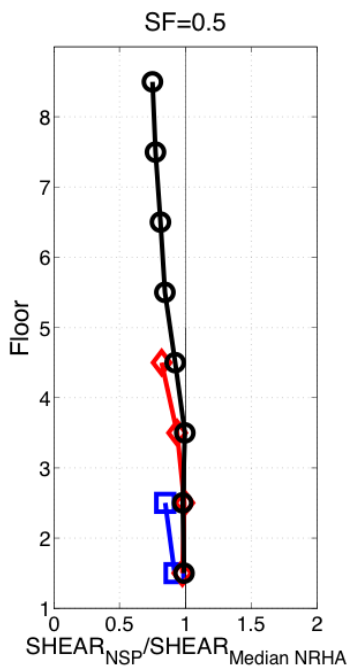

(b)

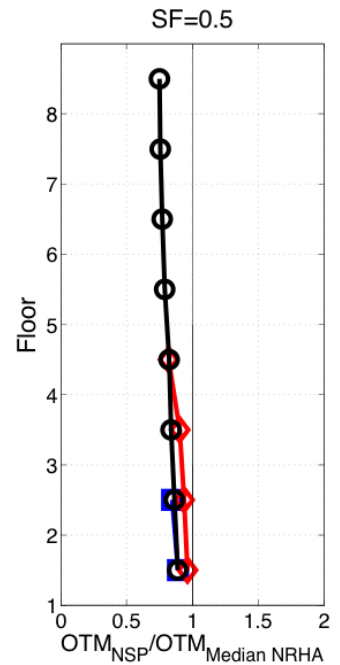

(c)

Figure 19 Ratio of elastic MRSA results and NRHA for the 8-story: (a) peak story drifts ( $\mathrm{SF}=0.5$ ), (b) peak story shears $(\mathrm{SF}=0.5)$, and (c) peak overturning moments $(\mathrm{SF}=0.5)$.

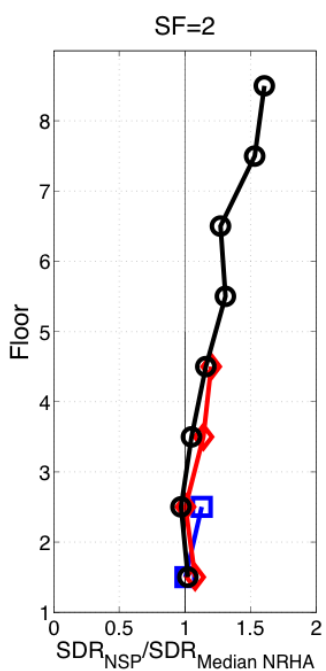

(a)

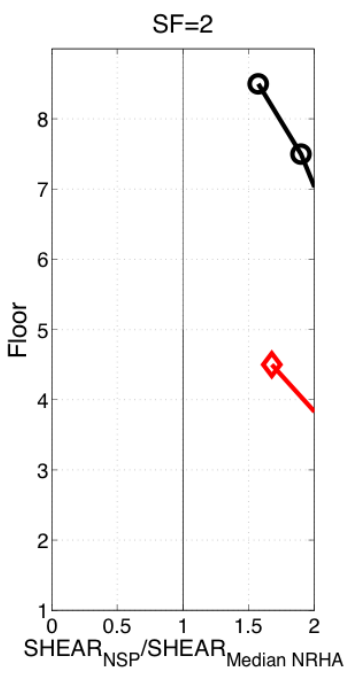

(b)

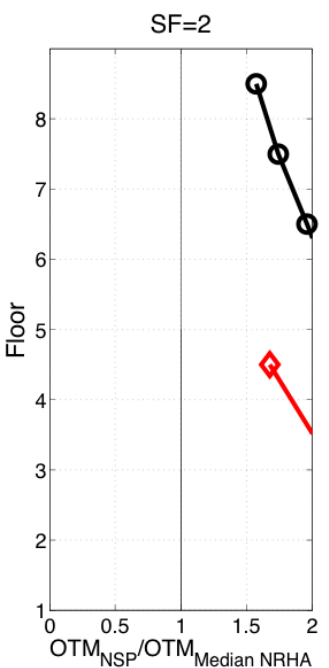

(c)

Figure 20 Ratio of elastic MRSA and NRHA for the 8-story: (a) peak story drifts ( $\mathrm{SF}=2.0)$, (b) peak story shears $(\mathrm{SF}=2.0)$, and $(\mathrm{c})$ peak overturning moments $(\mathrm{SF}=2.0)$.

For the 2-story frame, peak story drifts were estimated accurately just as occurred with first mode and multiple mode pushover analysis. While story shears and overturning moments were estimated accurately at a scale factor of 0.5 (Figure 17b,c and Figure 19b,c), the assumption of linear elastic response in every mode led to overestimation of story shears and overturning moments at higher scale factors (Figure 18b,c and Figure 20b,c). For elastic response and inelastic response where the equal displacement rule applies $\left(C_{1}=1.0\right)$ elastic modal response spectrum analysis and multiple mode pushover analysis provide identical estimates of peak displacements and drifts. For the 4-story frame, accurate estimates of floor displacements and story drifts were obtained at all scale factors. Story shears were underestimated at the upper stories at a scale factor of 0.5 , and were overestimated at scale factors of 1.0 and 2.0. Overturning moments were slightly underestimated at the lower floors at 
a scale factor of 0.5 , and are grossly overestimated at scale factors of 1.0 and 2.0 . For the 8 -story frame, story drifts were underestimated at a scale factor of 0.5 , estimated reasonably accurately at a scale factor of 1.0, and overestimated at the upper stories at a scale factor of 2.0. Story shears and overturning moments were generally underestimated by modal response spectrum analysis at a scale factor of 0.5 , and generally are overestimated at scale factors of 1.0 and 2.0.

These results suggest the possibility of a more efficient application of multimode pushover analysis for regular frames that have relatively uniform story drift demands. Therein, drift profiles are determined using elastic modal response spectrum analysis based on extrapolations to spectral amplitudes large enough to cause yielding in a nonlinear static pushover analysis, and these drift profiles are applied in a pushover analysis to estimate forces and moments, as suggested in Goel and Chopra (2005).

\section{Discussion of NSP accuracy}

The accuracy (or inaccuracy) of the NSP predictions may be assessed relative to the full distribution of NRHA results. For example, a $25 \%$ error in the median estimate of a given response quantity may initially seem excessive, but becomes perfectly adequate if the corresponding NRHA results show a $40 \%$ dispersion. To facilitate a fair comparison for all cases, we turn to the concept of confidence intervals (Benjamin and Cornell 1970). For each EDP, the minimum number of records (i.e. sample size) is determined that establishes a $90 \%$ confidence interval that contains the NSP result, centered on the NRHA median. Formally, each interval is estimated as:

$$
E D P_{50} \exp \left(\mp t_{0.95,43} \cdot \beta_{E D P} / \sqrt{N}\right), \text { where } N=1, \ldots, 44
$$

$E D P_{50}$ is the median value of the 44 values of EDP response and $\beta_{\mathrm{EDP}}$ is the corresponding standard deviation of the $\log$ of the data. The quantity $t_{0.95,43} \approx 1.6811$ is the $95 \%$ variate (i.e. the inverse of the cumulative distribution function) of the Student's- $t$ distribution with 44-1 degrees of freedom. In each case, the maximum equivalent number of records $N$ is sought such that the NSP response remains within the above limits.

The results, expressed as the median number of records over all stories and $S F=1,2$ are shown for each EDP type in Figure 21. Values less than or equal to 7, the minimum requirement of modern seismic codes, are judged to be of low quality. Mediocre accuracy is achieved up to 16 records while good predictions correspond to higher numbers. Anything above 30 records is considered to be nearperfect. For the 2-story, the results are good, as expected, for all NSPs. Regarding the 4-story, while locally some responses may not be perfectly captured, all methods achieve good performance for displacements and story drifts. However, results are worse for story shears and overturning moments; MPA and CMA at least provide mediocre performance. When moving to the 8-story, only displacements are consistently estimated at a mediocre or better level; drifts, shears and moments are esti- 
mated relatively poorly, with the MPA performing best for shears and overturning moments. Finally, it is remarkable that MRSA achieves a near-perfect estimation of displacements and drifts regardless of the number of stories. Still, this is should not be generalized as it can be attributed to the regularity of the buildings and the absence of any significant localization of damage.

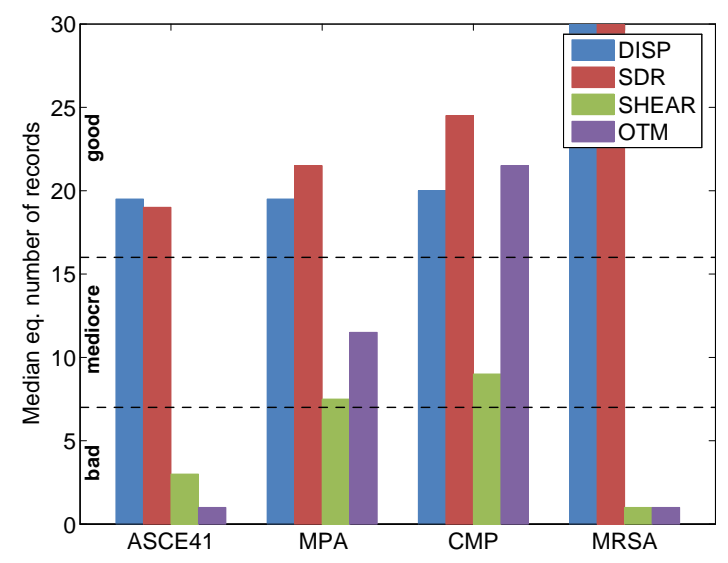

(a) 4-story

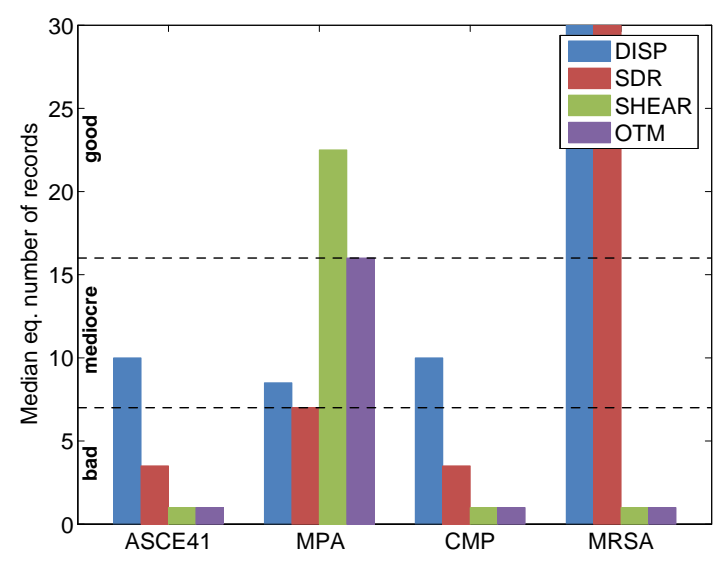

(b) 8-story

Figure 21: The accuracy in the NSP predictions expressed in terms of the equivalent number of records needed for NRHA to achieve the same accuracy. For each building and EDP type the median number of records is calculated over all stories and $S F=1,2$.

It should be noted that the approach described above excels at judging the results of the NSPs relative to those of NRHA. However, important limitations should be recognized: (1) for quantities with relatively little dispersion in NRHA (e.g. overturning moments), relatively small absolute departures from the NRHA median will be identified as a poor result (i.e. comparable to NRHA using few records), (2) the sign of the error as well as the potential consequences are not considered. Underestimation may result in unrecognized damage which may or may not be significant, while overestimation may result in needless retrofit measures, and (3) since medians over all stories for scale factors of 1 and 2 are taken, locally significant errors may be missed. Nevertheless, the results of Figure 19 clearly indicate the potential inaccuracies associated with different response quantities and the influence of the number of stories (or the presence of higher modes).

Considering the results from a different perspective, some important limitations on NSPs can be identified: (1) higher modes have very little contribution to some quantities such as floor displacements and hence very good estimates of peak floor displacements can be obtained with single-mode pushover analyses, and (2) many other response quantities have appreciable higher-mode contributions and as a result the peak values of various response quantities occur at different times and may deviate significantly from the first-mode estimates. Thus, it may not even be possible for singlemode static pushover analyses to capture the dynamics of the response. For example, NRHA peak story drifts, when summed over the height of the structure, can greatly exceed the peak roof drift. Moreover, the patterns of peak story shears and overturning moments, if considered statically, are in- 
consistent. That is to say that integration of the peak story shears produces a moment diagram that differs significantly from the empirical peak moment diagram. Thus, a single-mode static pushover method that is tuned to give good results for some response quantities will undoubtedly give poor estimates of other response quantities. Finally, we note that different modeling choices, e.g. lumped or distributed plasticity elements, may produce different estimates of response. To the extent that such differences do not result in the development of different inelastic mechanisms, they are not expected to affect qualitatively our relative findings of NSP against NRHA, especially for the pre-collapse intensity levels considered.

\section{CONCLUSIONS}

A comparison between results obtained using various NSP methods and nonlinear response history analysis has been presented. It is shown that the accuracy of NSP methods depends on the properties of the building, the EDP of interest, and the level of inelastic demand. Both standard, first modebased, and more elaborate NSPs were included in the comparison. The buildings considered form a simple basic test for the static pushover methods. For such low- and mid-rise structures all NSP's were expected to perform well, especially in the in the near post-nominal-yield region. However, it is concluded that no simple method exists that is consistently reliable and generally applicable to multistory buildings; therefore NRHA remains the most viable approach for detailed seismic performance evaluation. NSPs can be used to provide insight to the building's characteristics and potential vulnerabilities, helping the engineer to understand how the system will respond from a global perspective, and remain useful for preliminary design to limit displacement demands in performance-based earthquake engineering. Moreover, engineers must always have in mind that any analysis results may vary from the "exact" due to the large uncertainty inherent in the problem and the limitations of their numerical models and software. All in all, while important conclusions can be derived from NSP results, appropriate care is advised in all applications of NSP methods when used for the quantitative, rather than the qualitative, estimation of a structure's seismic performance. Such application is being considered for the 2013 update to ASCE 31 and 41.

\section{ACKNOWLEDGMENTS}

This paper relies, in part, on results obtained under Task Order 6 of the NEHRP Consultants Joint Venture (a partnership of the Applied Technology Council and Consortium of Universities for Research in Earthquake Engineering), under Contract SB134107CQ0019, Earthquake Structural and Engineering Research, issued by the National Institute of Standards and Technology. The views expressed do not necessarily represent those of the organizations represented above. The authors also gratefully acknowledge Dr. Curt Haselton for providing the OpenSees input files of the RC moment frames. 


\section{REFERENCES}

Antoniou, S., Pinho, R. 2004. "Development and Verification of a Displacement-Based Adaptive Pushover Procedure", Journal of Earthquake Engineering, 8(5): 643-661.

ASCE 2003, Seismic Evaluation of Existing Buildings, ASCE Standard ASCE/SEI 31-03, American Society of Civil Engineers/Structural Engineering Institute, Reston, VA.

ASCE 2007, Seismic Rehabilitation of Existing Buildings, ASCE Standard ASCE/SEI 41-06, American Society of Civil Engineers, Reston, Virginia.

ASCE 2010, Minimum Design Loads for Buildings and Other Structures, ASCE Standard ASCE/SEI 7-10, American Society of Civil Engineers, Reston, VA.

Aschheim, M., Tjhin, T., Comartin, C., Hamburger, R., Inel, M. 2007. “The scaled nonlinear dynamic response”, Engineering Structures, 29:1422-1441.

Aschheim, M.A., Black, E.F., Cuesta, I. 2002. "Theory of principal components analysis and applications to multistory frame buildings responding to seismic excitation", Engineering Structures, 24:1091-1103.

ATC (1996). "Seismic Evaluation and Retrofit of Concrete Buildings", ATC 40 Report, Volumes 1 and 2, Applied Technology Council, Redwood City, CA.

Aydınoglu, M.N. 2003. “An Incremental Response Spectrum Analysis Procedure Based on Inelastic Spectral Displacements for Multi-Mode Performance Evaluation”, Bulletin of Earthquake Engineering, 1: 3-36.

Benjamin, J., Cornell, C.A. 1970, Probability, statistics, and decisions for civil engineers, McGraw Hill, NY.

Bhatt, C., Bento, R. 2012. "Comparison of Nonlinear Static Methods for the Seismic Assessment of Plan Irregular Frame Buildings with non seismic details", Journal of Earthquake Engineering, 16(1): 15-39.

Causevic, M., Mitrovic. S. 2011. "Comparison between Non-Linear Dynamic and Static Seismic aAnalysis of Structures aAccording to European and US Provision", Bulletin of Earthquake Engineering, 9(2): 467-489.

Chopra, A.K., Goel, R.K. 2002. A modal pushover analysis procedure for estimating seismic demands for buildings. Earthquake Engineering and Structural Dynamics. 31(3): 561-582.

Diotallevi, P.P., Landis, L. Pollio, B. 2008. "Evaluation of conventional and advanced pushover procedures for regular and irregular RC frames", Proceeding of the $14^{\text {th }}$ World Conference on Earthquake Engineering Innovation Practice and Safety, Beijing, China.

Eurocode 8 2004. "Design of structures for earthquake resistance — Part 1: General rules, seismic actions and rules for buildings". CEN. Brussels: European Committee for Standardization.

Fajfar, P. 1999. "Capacity spectrum method based on inelastic demand spectra", Earthquake Engineering and Structural Dynamics, 28(9): 979-993.

Fajfar, P., Fischinger, M. 1988. "N2 - A method for non-linear seismic analysis of regular buildings", Proceedings of the 9th World Conference on Earthquake Engineering, 5:111-116.

FEMA 2005. Improvement of Nonlinear Static Seismic Analysis Procedures. FEMA 440 Report prepared by the Applied Technology Council for the Federal Emergency Management Agency, Washington, D.C.

FEMA 2009, Quantification of Seismic Performance Factors, FEMA P-695 Report, prepared by the Applied Technology Council for the Federal emergency Management Agency, Washington, D.C.

FEMA 2009. NEHRP Recommended Seismic Provisions for New Buildings and Other Structures, Building Seismic Safety Commission, FEMA P-750, Federal Emergency Management Agency, Washington, D.C.

Fragiadakis, M., Ioannidou, D., Papadrakakis, M. 2007. Assessment of Nonlinear Static Analysis Procedures in the Framework of Performance-Based Design. 8th National Congress on Mechanics (HSTAM2007), June 12-17, 2007, Patras, Greece.

Goel, R.K, Chopra, A.K. 2005. "Extension of Modal Pushover Analysis to Compute Member Forces”, Earthquake Spectra. 21(1): $125-139$.

Goel, R.K. 2005. "Evaluation of modal and FEMA pushover procedures using strong-motion records of buildings", Earthquake Spectra, 21(3): 653-684.

Haselton, C., Deierlein, G. 2007. "Assessing Seismic Collapse Safety of Modern Reinforced Concrete Moment Frame Buildings”, Report No. 156, John A. Blume Earthquake Engineering Center. Department of Civil and Environmental Engineering. Stanford University.

Haselton, C.B., Liel, A.B., Deierlein, G.G., Dean, B.S., Chou, J.H. 2011. "Seismic Collapse Safety of Reinforced Concrete Buildings: I. Assessment of Ductile Moment Frames". Journal of Structural Engineering, 137:481-492.

Hernández-Montes, E., Kwon, O-S, Aschheim, M. 2004, "An Energy-Based Formulation for First- and Multiple-Mode Nonlinear Static (Pushover) Analyses, Journal of Earthquake Engineering, 8(1):69-88.

International Code Council 2002. 2003 International Building Code (IBC). International Code Council: Country Club Hills, IL.

Isaković, T., Fischinger, M. 2011. "Applicability of Pushover Methods to the Seismic Analyses of an RC Bridge, Experimentally Tested on Three Shake Tables", Journal of Earthquake Engineering, 15 (2): 303-320.

Kalkan, E., Kunnath, S.K. 2007. "Assessment of current nonlinear static procedures for seismic evaluation of buildings”, Engineering Structures, 29(3): 305-316.

Krawinkler, H., Seneviratna, G.D.P.K. 1998. "Pros and cons of a pushover analysis of seismic performance evaluation", Engineering Structures, 20(4-6): 452-464.

Kreslin, M., Fajfar, P. 2011. "The extended N2 method taking into account higher mode effects in elevation”, Earthquake Engineering and Structural Dynamics, 40(14): 1571-1589.

Kunnath, S., Erduran, E. 2008. "Pushover Procedures for Seismic Assessment of Buildings: Issues, Limitations and Future Needs", Nonlinear Static Methods for Design/Assessment of 3D Structures, In: R. Bento \& R. Pinho (ed), 5-6 May 2008 Lisbon, Portugal.

Kunnath, S.K. 2004. "Identification of Modal Combinations for Nonlinear Static Analysis of Building Structures", Computer-Aided Civil and Infrastructure Engineering, 19(4): 246-259.

Lagaros, N.D., Fragiadakis, M. (2011). "Evaluation of static pushover methods for performance based seismic design”, Soil Dynamics and 
Earthquake Engineering, 31(1): 77-90.

Lignos, D.G., Krawinkler, H. 2009. "Sidesway collapse of deteriorating structural systems under seismic excitations", Rep.No.TR 172, The John A. Blume Earthquake Engineering Research Center, Stanford University.

McKenna, F., Fenves, G.L. 2001. The OpenSees Command Language Manual (1.2. edn).

NIST 2010. ATC-76-6: Applicability of Nonlinear Multiple-Degree-of-Freedom Modeling for Design, Report No. NIST GCR 10-917-9, prepared for the National Institute of Standards and Technology by the NEHRP Consultants Joint Venture, Gaithersburg, MD.

Önem, G. 2008. "Evaluation of Practice-Oriented Nonlinear Analysis Methods for Seismic Performance Assessment", PhD Dissertation, Bogazici University, Instanbul, Turkey.

Pinho, R., Casarotti, C., Antoniou, S. 2007. "A Comparison of Single-Run Pushover Analysis Techniques for Seismic Assessment of Bridges”, Earthquake Engineering and Structural Dynamics, 36(10): 1347-1362.

Pinho, R., Monteiro, R., Casarotti, C., Delgado, R. 2009. "Assessment of continuous span bridges through nonlinear static procedures", Earthquake Spectra, 25(1):143-159.

Poursha, M., Khoshnoudian, F., Moghadam, A.S. 2009. "A Consecutive Modal Pushover Procedure for Estimating the Seismic Demands of Tall Buildings", Engineering Structures, 31(2): 591-599. 